\title{
Application of WHO MUAC for age $-Z$ score chart in diagnosis of SAM in Indian children: a comparative study with IAP classification
}

\author{
Shareef FM ${ }^{1}$, Manoj GM² \\ ${ }^{1}$ Dr. Fahad Muhamed Shareef A T, Junior Resident, Department of Paediatrics, Silchar Medical College and Hospital, \\ Silchar, Assam, ${ }^{2}$ Dr. Manoj G M, Junior Resident, Department of Paediatrics, Silchar Medical College and Hospital, \\ Silchar, Assam, India.
}

Address for Correspondence: Dr. Fahad Muhamed Shareef AT; drfahadms@gmail.com

\begin{abstract}
Background: Mid upper arm circumference (MUAC) is a quick and easy method to determine malnutrition. Though considered age independent earlier, recently World Health Organization (WHO) has prepared MUAC Z score chart for age group between 3 months to 5 years. Objective: To diagnose severe acute malnutrition (SAM) by using new WHO MUAC-Z score and to compare its efficacy with IAP classification for the diagnosis of SAM. Methods: A cross sectional study was conducted in a tertiary care center of north east India. 500 children in the age group of 1 to 5 years, attending inpatient department, were included and a detailed history, clinical examination and anthropometry were taken. SAM was defined by IAP weight for age classification as grade 3 and 4 and by WHO MAUC-Z score <-3SD. Results: Prevalence of SAM according to IAP grading was $11.8 \%$ and according to WHO MUAC was $17 \%$ with difference being significant $(\mathrm{p}<0.05)$. The mean values of weight and MUAC were less than WHO median values which suggest that there is significant malnutrition in the study population. Prevalence of SAM was more in $<2$ years of age. Conclusion: MUAC is more sensitive than IAP grading in early diagnosis of SAM and facilitate early and effective treatment. New WHO MUAC-Z score alone can be used in screening malnutrition.
\end{abstract}

Key words: Severe Acute Malnutrition (SAM), Mid Upper Arm Circumference (MUAC), Indian Academy of Pediatrics (IAP), weight, anthropometry.

\section{Introduction}

Malnutrition is a man-made disease which often starts in the womb and ends in the tomb [1]. Under nutrition and malnutrition form the most serious human health and social problem that affect vast areas of the world with much more prevalence in the developing and underdeveloped countries. India is one among the many countries where child malnutrition is severe and also malnutrition is a major underlying cause of child mortality [2]. Nearly $60-70 \%$ of preschool children suffer from nutritional deficiencies which range from mild to moderate PEM while $2-3 \%$ suffers from severe forms.

It is obvious that there is urgent need to focus on the nutritional and overall developmental needs of child. Anthropometry is the study of the measurement of the human body in terms of the dimensions of bone,

Manuscript received: $10^{\text {th }}$ November 2016

Reviewed: $24^{\text {th }}$ November 2016

Author Corrected; $8^{\text {th }}$ December 2016

Accepted for Publication: $22^{\text {nd }}$ December 2016 muscle, and adipose (fat) tissue. Several indices and ratios can be derived from anthropometric measurements [3]. The anthropometric measures useful in evaluating PEM include weight for age, height/length for age, weight for height/length, mid upper arm circumference (MUAC) and so on. Based on these measurements, the indices can be categorised into age dependent and age independent. Accordingly grading of PEM is done by various classifications like IAP Classification, WHO Classification and Welcome Trust Classification [1].

IAP classification is based on weight for age, and weight can be affected by edema, organomegaly, tumor growth and error of weighing machine. It involves calculating median standard, division with measured value and calculating percent which may cause error. But MAUC don't have such limitations and measurement is quick and easy and it is one good indicator of malnutrition [4]. Previously MUAC was 
age independent, but in 2007 one of the studies of WHO has shown age dependent character of MUAC and $\mathrm{WHO}$ prepared $\mathrm{Z}$ score chart for age group between 3 months to 5 year [5].

We conducted the study to validate new WHO MUAC$\mathrm{Z}$ score chart in diagnosis of SAM in local children (from south part of Assam including Cachar, Hailakandhi and Karimganj district) and its comparison with IAP classification for better diagnosis of malnutrition.

\section{Materials and Methods}

The present study was conducted in Silchar Medical College and Hospital situated in Silchar, Cachar district in Assam, India. It was a hospital based cross sectional study. The children attending the inpatient department of pediatrics were examined at one point of time and the data were assessed.

The study was conducted from June 2013 to June 2014. Sample size for the cross-sectional prevalence study was calculated using the formula, Sample size (n) $=4 \mathrm{PQ} / \mathrm{d}^{2}$. With an expected prevalence of under nutrition $(\mathrm{P})$ of $50 \%$ and a relative precision $(\mathrm{d})$ of $10 \%$ of $P$, the required sample size was calculated as 400 .

The total number of patients included in the present study was 500. 500 Children in the age group of $1-5$ years attending inpatient department of Silchar Medical College were taken randomly into study.

Age was taken as inclusion criteria as MUAC was earlier said to be age independent in 1- 5 years age group. Children suffering from chronic systemic illnesses like chronic kidney disease, congenital heart disease, and malabsorption syndromes were excluded from the study.

The data for the preschool children under study were collected on a pretested schedule. Information was obtained by history, thorough clinical examination and anthropometric measurements of the children done by a pediatric resident. Informed consent was taken from the parents of the study population. Ethical clearance was taken from ethical committee of college. Weight of each child was taken using an electronic weighing machine, removing all the clothes.

Infantometer was used for measuring length in 1 to 2 years while height was measured using stadiometer in 2 to 5 years age group. MUAC was measured in the left arm taking horizontal measurement of midpoint of olecranon process and acromion, using a non stretchable measuring tape.

In children between the ages of 6 months to 59 months, Severe Acute Malnutrition (SAM) is defined as: $(i)$ Weight/height or weight/length $<-3$ Zscore, using the WHO Growth Charts; or (ii) Presence of visible severe wasting; or (iii) Presence of bipedal edema of nutritional origin; or (iv) Mid- upper arm circumference (MUAC) $<115 \mathrm{~mm}[5)$

WHO classification for malnutrition considers standard deviation or $\mathrm{Z}$ scores for classifying children in moderate (between -2 to $-3 \mathrm{SD}$ ) and severe (<-3SD) categories, whereas IAP Weight for age Classification considers $0 \mathrm{SD}$ (standard deviation) or $50^{\text {th }}$ percentile as 100 percent of expected weight for age and then grade I (70-80\% of expected), grade II (60-70\% of expected), grade III (50-60\% of expected) and grade IV ( $<50 \%$ of expected) PEM (protein energy malnutrition) are classified.

In these grades I and II are considered moderate while grade III and IV are considered severe malnutrition [1].

We defined SAM as:

- IAP class 3 and $4[1]$.

- MUAC is below - 3SD according to WHO MUAC-Z score chart [5].

WHO mean values were considered as expected weight, height and length for calculation of IAP grading. The statistical analysis was done with the help of a statistician and student $\mathrm{t}$ test was used to compare statistical significance.

A p value less than 0.05 was considered statistically significant.

\section{Result}

The study consisted of 500 children from 1 year to 5 years of age. They were divided into groups of 13 to 18 months, 19 to 24 months 25 to 30 months, 31 to 36 months, 37 to 48 months and 49 to 60 months for ease of calculation. Mean weight and standard deviation of children shown in table 1 . From the table it is evident that mean weight of boys was comparatively more than that of girls with $\mathrm{p}$ value, being significant. 
Table-1: Mean weight and standard deviation of male and female children from 1year to 5years of age.

\begin{tabular}{|c|c|c|c|c|c|c|c|}
\hline \multirow{3}{*}{$\begin{array}{c}\text { Age groups } \\
\text { (months) }\end{array}$} & \multicolumn{3}{|c|}{ Male } & \multicolumn{3}{|c|}{ Female } & \multirow[t]{3}{*}{ P value } \\
\hline & \multirow{2}{*}{ No. } & \multicolumn{2}{|c|}{ Weight (kg) } & \multirow{2}{*}{ No. } & \multicolumn{2}{|c|}{ Weight (kg) } & \\
\hline & & Mean & SD & & Mean & SD & \\
\hline $13-18$ & 86 & 8.34 & 2.14 & 62 & 7.42 & 2.07 & \multirow{6}{*}{$<0.05$} \\
\hline $19-24$ & 48 & 10.1 & 1.89 & 57 & 9.85 & 2.04 & \\
\hline $25-30$ & 37 & 10.8 & 1.79 & 44 & 9.26 & 2.35 & \\
\hline $31-36$ & 34 & 11.9 & 2.21 & 31 & 11.0 & 2.11 & \\
\hline $37-48$ & 31 & 13.1 & 2.66 & 22 & 12.4 & 2.31 & \\
\hline $49-60$ & 25 & 14.7 & 2.78 & 23 & 14.3 & 2.12 & \\
\hline Total & 261 & & & 239 & & & \\
\hline
\end{tabular}

Mean MUAC and standard deviation of children from 1 year to 5 years is shown in table 2 and it is seen that MUAC of male children are more than female children and difference was insignificant as $\mathrm{p}$ value is $>0.05$.

Table-2: Mean MUAC and standard deviation from 1 year to 5 years of age.

\begin{tabular}{|c|c|c|c|c|c|c|c|}
\hline \multirow{3}{*}{$\begin{array}{c}\text { Age } \\
\text { (months) }\end{array}$} & \multicolumn{3}{|c|}{ Male } & \multicolumn{3}{|c|}{ Female } & \multirow{3}{*}{$P$ value } \\
\hline & \multirow{2}{*}{ No. } & \multicolumn{2}{|c|}{ MUAC (cm) } & \multirow{2}{*}{ No. } & \multicolumn{2}{|c|}{ MUAC (cm) } & \\
\hline & & Mean & SD & & Mean & SD & \\
\hline $13-18$ & 86 & 13.5 & 1.62 & 62 & 13.3 & 2.02 & \multirow{6}{*}{$>0.05$} \\
\hline $19-24$ & 48 & 13.9 & 0.77 & 57 & 13.5 & 0.84 & \\
\hline $25-30$ & 37 & 14.3 & 1.01 & 44 & 13.7 & 1.63 & \\
\hline $31-36$ & 34 & 13.9 & 1.08 & 31 & 13.8 & 1.18 & \\
\hline $37-48$ & 31 & 14.0 & 0.78 & 22 & 14.0 & 1.06 & \\
\hline $49-60$ & 25 & 14.7 & 1.00 & 23 & 14.1 & 0.87 & \\
\hline
\end{tabular}

Then we calculated prevalence of SAM according to IAP classification and WHO MUAC-Z score as defined previously (table 3). It was seen that prevalence was more in age group of 13 to 30 months in both the classifications. The prevalence of SAM was more when WHO MUAC- Z score (17\%) was taken as criteria in comparison to IAP (11.8\%) and the difference was statistically significant $(\mathrm{p}<0.05)$.

Table 3: Prevalence of SAM according to IAP classification and according to WHO MUAC - $\mathrm{Z}$ score chart and their comparison.

\begin{tabular}{|c|c|c|c|c|}
\hline \multirow{2}{*}{$\begin{array}{c}\text { Age in } \\
\text { months }\end{array}$} & \multirow{2}{*}{ No. } & IAP & WHO MUAC-Z score & \multirow{2}{*}{ P value } \\
\cline { 2 - 4 } & & 29 & 12 \\
\hline $13-18$ & 148 & 7 & 15 & $<0.05$ \\
\hline $19-24$ & 105 & 12 & 9 & 5 \\
\hline $25-30$ & 81 & 6 & 6 & \\
\hline $31-36$ & 65 & 3 & $\mathbf{8 5}(\mathbf{1 7 \%})$ & \\
\hline $49-60$ & 53 & 2 & $\mathbf{5 9 ( 1 1 . 8 \% )}$ & \\
\hline
\end{tabular}




\section{Discussion}

The World Bank estimates that India is one of the highest ranking countries in the world for the number of children suffering from malnutrition. The prevalence of underweight children in India is among the highest in the world, and is nearly double that of Sub Saharan Africa with dire consequences for mobility, mortality, productivity and economic growth [6].

Normally used anthropometric index to define malnutrition is weight for age. Weight for age is one of the most important measurements in nutritional assessment. It is an important variable used in equations predicting macronutrient and fluid requirements and a valuable index in acute malnutrition. Weight, however does not distinguish between fat, protein, bone and water. It can also be influenced by fluid status, organomegaly and tumor growth. It is also important to note that conclusions cannot be made from isolated "once off" measurements and nutritional status cannot be determined without length or height. Current measurements must always be compared to previous values, and if it appears unusual, the measurements must be repeated [4].

The arm contains both subcutaneous fat and muscle; therefore a decrease in MUAC may reflect either a reduction in muscle mass, subcutaneous tissue or both. It is a simple, low-cost, objective method of assessing nutritional status. It can also be obtained quickly and non-invasively and can provide a more accurate assessment of nutritional status especially if it is difficult to obtain measurements for weight and height (e.g. in Cerebral palsy children). In certain settings, if age is not available, MUAC-for-height reference data is used. MUAC may be more appropriate for identifying severe malnutrition in children between 1-5 years and changes in MUAC measurements can be used to monitor progress during nutritional therapy [4].

So we conducted a study to validate the WHO MUAC$\mathrm{Z}$ score in defining SAM and its comparison with SAM defined from IAP classification. In the present study, the prevalence of PEM was highest in the age group of 13- 18 months and lowest in the age group $49-60$ months. The findings of other workers namely Ighogboja et al [7], and Bhattacharya et al [8] also suggested higher prevalence of PEM in the children below 2 years of age group. Malnutrition in children typically develops during the period from 6 to 18 months of age, when growth velocity and brain development are especially high as stated in Guideline: Updates on the Management of Severe Acute Malnutrition in Infants and Children by WHO 2013 [9]. As evident from table 3 , prevalence of SAM was more when WHO MUAC-Z score was taken as criteria as when compared to IAP classification and the difference is statistically significant ( $\mathrm{p}$ value $<0.05$ ) indicating that WHO MUAC-Z score detects more cases of SAM compared to IAP classification.

Dominique Roberfroid et al did a study of Utilization of mid-upper arm circumference versus weight-for-height in nutritional rehabilitation programmers: a systematic review of evidence and concluded that MUAC could be used adequately as a stand-alone criterion for SAM children to be admitted to and discharged from nutritional rehabilitation programmers [10]. Sylvie Goossens et al also did a similar study comparing MUAC with weight for height $\mathrm{z}$ (WHZ) scores in therapeutic feeding programmes $\mathrm{u}$ in Burkina and found out that MUAC is a useful alternative to weight for height $\mathrm{z}$ score [11].

Andre Brenda et al had done a similar study comparing effectiveness of MUAC over weight for height and found there is no benefit in using both WHZ less than 3 and MUAC less than $115 \mathrm{~mm}$ over MUAC alone [12]. Jeremy Powell-Tuck et al had done a study comparing MUAC, body mass index (BMI) and weight loss as indices of under nutrition in acutely hospitalised patients. They found that MUAC correlates closely with BMI and is easier to measure and predicts poor outcome better [13].

All the studies above showed that MUAC is a better indicator of malnutrition similar to our study. Large scale studies have yet to be done comparing the effectiveness of MUAC for age to weight for age or weight for height. This study had few limitations. The study was done in hospitalised children which could have affected their weight to a minor extent. The study population was only 500 and inclusion of more children would have benefitted the study. The age group used was between 13 to 60 months of age. The incorporation of 6 to 12 months of age would have given more yield.

\section{Conclusion}

Over all SAM was diagnosed more from WHO MUAC$\mathrm{Z}$ score $(17 \%)$ than IAP classification $(11.8 \%)$. This indicate that MUAC is more sensitive than IAP 
classification in diagnosing SAM leading to early diagnosis and better treatment and follow up of SAM children. So new WHO MAUC-Z score alone can be used to screen malnutrition and specially to define SAM. However, there is need for larger and more studies to substantiate this conclusion.

\section{Funding: Nil, Conflict of interest: Nil Permission from IRB: Yes}

\section{References}

1. Elizabeth KE, Nutrition and Child Development. $4^{\text {th }}$ ed. India: Paras; 2010. p. 163-260.

2. United Nations International Children's Emergency Fund (UNICEF), the state of the world's children, oxford university press, 0xford, 2005.

3. National Health and Nutrition Examination Survey Anthropometric procedure Manual; CDC, January 2007.

4. Anthropometry Guideline Paediatrics [Internet]. 2016 [cited 10 July 2016]. Available from: http://www.adsa. org.za/Portals/14/Documents/Clinical20Guideline20Ant hropometry.pdf

5. WHO|Arm circumference-for-age [Internet]. Who. int. 2016 [cited 10 July 2016]. Available from: http://www.who.int/childgrowth/standards/acfor_age/en

6. South Asia - India: Malnutrition Report [Internet]. Web.worldbank.org. 2016 [cited 10 July 2016]. Available from: "World Bank Report". Source: The World Bank (2009). World Bank Report on Malnutrition in India.
7. Ighogboja SI. Some factors contributing to proteinenergy malnutrition in the middle belt of Nigeria. East African medical journal. 1992 Oct.;69(10):566-71.

8. Bhattacharya AK. Studies on Kwashiorkor and Marasmus in Calcutta (1957 - 74) - Aetiology and Clinical studies. Indian Pediatrics. 1975 Nov.;12(11): $1103-13$.

9. Guideline: Updates on the Management of Severe Acute Malnutrition in Infants and Children.Geneva: World Health Organization; 2013.

10. Roberfroid D, Hammami N, Lachat C, Prinzo ZW, Sibson V, Guesdon B, Goosens S, Kolsteren P. Utilization of mid-upper arm circumference versus weight-for-height in nutritional rehabilitation programmes: a systematic review of evidence. Geneva: World Health Organization. 2013 Oct.

11. Goossens S, Bekele Y, Yun O, Harczi G, Ouannes M, Shepherd S. Mid-Upper Arm Circumference Based Nutrition Programming: Evidence for a New Approach in Regions with High Burden of Acute Malnutrition. PLoS ONE. 2012;7(11):e49320.

12. Briend A, Maire B, Fontaine O, Garenne M. Midupper arm circumference and weight-for-height to identify high-risk malnourished under-five children. Maternal \& Child Nutrition. 2011;8(1):130-133.

13. Powell-Tuck J. A comparison of mid upper arm circumference, body mass index and weight loss as indices of undernutrition in acutely hospitalized patients. Clinical Nutrition. 2003;22(3):307-312.

\section{How to cite this article?}

Shareef FM, Manoj GM.Application of WHO MUAC for age -Z score chart in diagnosis of SAM in Indian children: a comparative study with IAP classification. J PediatrRes.2016;3(12):880-884.doi:10.17511/ijpr.2016.i12.04. 